\title{
Treatment of venous thromboembolism in cancer patients: a systematic review and meta-analysis on the efficacy and safety of different direct oral anticoagulants (DOACs)
}

\author{
Xiaojun Song, Zhili Liu, Rong Zeng, Jiang Shao, Bao Liu, Yuehong Zheng, Changwei Liu, Wei Ye \\ Department of Vascular Surgery, Peking Union Medical College Hospital, Beijing, China \\ Contributions: (I) Conception and design: X Song, W Ye; (II) Administrative support: C Liu, W Ye; (III) Provision of study materials or patients: Z \\ Liu, R Zeng, J Shao; (IV) Collection and assembly of data: B Liu, Y Zheng; (V) Data analysis and interpretation: X Song, Z Liu; (VI) Manuscript \\ writing: All authors; (VII) Final approval of manuscript: All authors. \\ Correspondence to: Wei Ye. Department of Vascular Surgery, Peking Union Medical College Hospital, no. 1 Shuaifuyuan, Dongcheng District, Beijing \\ 100730, China. Email: yewill18@126.com.
}

Background: To evaluate the efficacy and safety of different direct oral anticoagulants (DOACs) compared with low molecular weight heparins (LMWHs) in the treatment of venous thromboembolism (VTE) in cancer patients.

Methods: Literature was searched in databases including Cochrane Library, EMBASE (Ovid), and MEDLINE (PubMed). Eligible studies were included, and data were collected independently by 2 reviewers. We conducted a systematic review of the efficacy and safety of DOACs in the treatment of VTE in cancer patients. The odds ratios (ORs) of different DOACs compared with LMWHs for VTE, deep vein thrombosis (DVT), pulmonary embolism (PE) recurrence, major bleeding, and clinically relevant non-major bleeding (CRNMB), were calculated in meta-analyses and subgroup analyses.

Results: A total of 18 articles were eligible for analyses, including 4 randomized controlled trials (RCTs) and 14 retrospective studies. Both RCTs and retrospective studies confirmed that DOACs decreased the risk of VTE recurrence [RCTs: OR, 0.60; 95\% confidence interval (CI), 0.45-0.80; retrospective studies: OR, 0.73; 95\% CI, 0.59-0.90] and DVT recurrence (RCTs: OR, 0.54; 95\% CI, 0.36-0.80; retrospective studies: OR, 0.20; 95\% CI, 0.06-0.63), but not PE recurrence or fatal PE in cancer patients. Subgroup analyses revealed an important role of rivaroxaban in decreasing recurrent VTE. Meanwhile, major bleeding events were not increased in the DOAC group, but the risks of CRNMBs were significantly elevated. Subgroup analyses confirmed the role of rivaroxaban in increasing the risk of major bleeding events and CRNMBs.

Conclusions: Compared with LMWHs, DOACs (especially rivaroxaban) significantly reduce the risk of VTE and DVT, but not PE recurrence, in patients with cancer. Although DOACs did not increase the major bleeding events in pooled analysis, rivaroxaban showed an elevated risk of this adverse effect in subgroup analysis. In addition, the risk of CRNMB events was increased after the application of DOACs including rivaroxaban.

Keywords: Direct oral anticoagulant (DOAC); low molecular weight heparin (LMWH); venous thromboembolism (VTE); cancer; major bleeding events

Submitted Dec 01, 2020. Accepted for publication Jan 21, 2021.

doi: 10.21037/atm-20-8156

View this article at: http://dx.doi.org/10.21037/atm-20-8156 


\section{Introduction}

Venous thromboembolism (VTE) in cancer patients is associated with increased mortality (1). It has been estimated that the incidence of recurrent VTE is about $9.6 \%$, with the incidence being as high as $22.1 \%$ within 6 months of initial cancer diagnosis (2). The common forms of VTE include deep vein thrombosis (DVT) and pulmonary embolism (PE) (3). Given the detrimental effect of VTE on cancer patients, anticoagulant therapy is recommended for the treatment of VTE in patients with active cancer (4). However, anticoagulant treatment leads to the risk of bleeding (5), which is the most severe adverse effect in clinical practice. Therefore, in cancer patients, the balance between anticoagulation and bleeding prevention should carefully be considered in the management of VTE.

Low molecular weight heparins (LMWHs) are the traditionally recommended therapy for the VTE treatment, and have been shown to significantly decrease the recurrence of VTE (6). Nevertheless, direct oral anticoagulants (DOACs), which include rivaroxaban, edoxaban, apixaban, and others, are being increasingly recognized as a promising strategy for decreasing VTE events in cancer patients, with many recent studies demonstrating that DOACs are comparable with LMWHs in the efficacy of VTE treatment in cancer patients (7-9). However, there is a lack of systematic reviews and meta-analyses investigating the relative efficacy and adverse events of different DOACs for the treatment of VTE in patients with cancer.

In order to clarify the efficacy and safety of different DOACs for the treatment of recurrent VTE in cancer patients, we systematically reviewed and performed a meta-analysis using subgroup analyses of the observational studies and randomized controlled trials (RCTs) comparing DOACs with LMWHs in treating VTE. Through this, we hope to provide updated evidence for clinical decisionmaking on anticoagulant therapy in cancer patients.

We present the following article in accordance with the PRISMA reporting checklist (available at http://dx.doi. org/10.21037/atm-20-8156).

\section{Methods}

\section{Search strategy}

This systematic review and meta-analysis were conducted according to the Preferred Reporting Items for Systematic Reviews and Meta-Analyses (PRISMA) (10). The literature from the Cochrane Library, EMBASE (Ovid), and
MEDLINE (PubMed) databases with a publication date from initiation to October 1, 2020 was systematically searched. We used the keywords "oral anticoagulant", or "Factor Xa inhibitor" or "rivaroxaban" or "edoxaban" or "apixaban" or "dabigatran" and "low molecular weight heparin" and "cancer" or "tumor" or "neoplasm" and "venous thromboembolism" or "vein thrombosis" to search all the potentially relevant literature.

\section{Study collection and data extraction}

Two investigators independently analyzed the relevant literature for further study collection and data extraction. When an investigator was uncertain of the inclusion or exclusion of an article, or there was a discrepancy between the 2 reviewers about an article, it was resolved by in-depth discussion. The relevant literature was first screened by title and then identified with further reading of the abstract. After a review of the full text, an article was deemed eligible if it met the following inclusion criteria: (I) a retrospective observational study or a prospective RCT; (II) investigating the efficacy and safety of oral anticoagulant and LMWH for the treatment of VTE in cancer patients; and (III) a followup for anticoagulation therapy $\geq 6$ months. Literature was not eligible for analysis if it met any of the following exclusion criteria: (I) DOAC and LMWH used for prophylaxis of VTE; (II) incomplete data insufficient for systematic review and meta-analysis; (III) reviews, case reports, or abstracts for academic conferences or other research types unsuitable for systematic review and meta-analysis. For the eligible literature, study type, period, grouping, sample size, treatment dose, treatment duration, follow-up, recurrent VTE, recurrent PE, major bleeding, and clinically relevant non-major bleeding (CRNMB) events were extracted.

\section{Main outcomes}

The main outcomes for evaluating efficacy included recurrence of VTE, deep venous thrombosis or PE within 6 months, and fatal PE. The outcomes for safety included major bleeding and CRNMB events.

\section{Quality assessment}

In order to assess the risk of bias, we used the Risk of Bias in Non-randomized Studies of Interventions (ROBINS-I) for evaluating the observational cohort studies. ROBINS-I assesses bias from confounding in the selection 


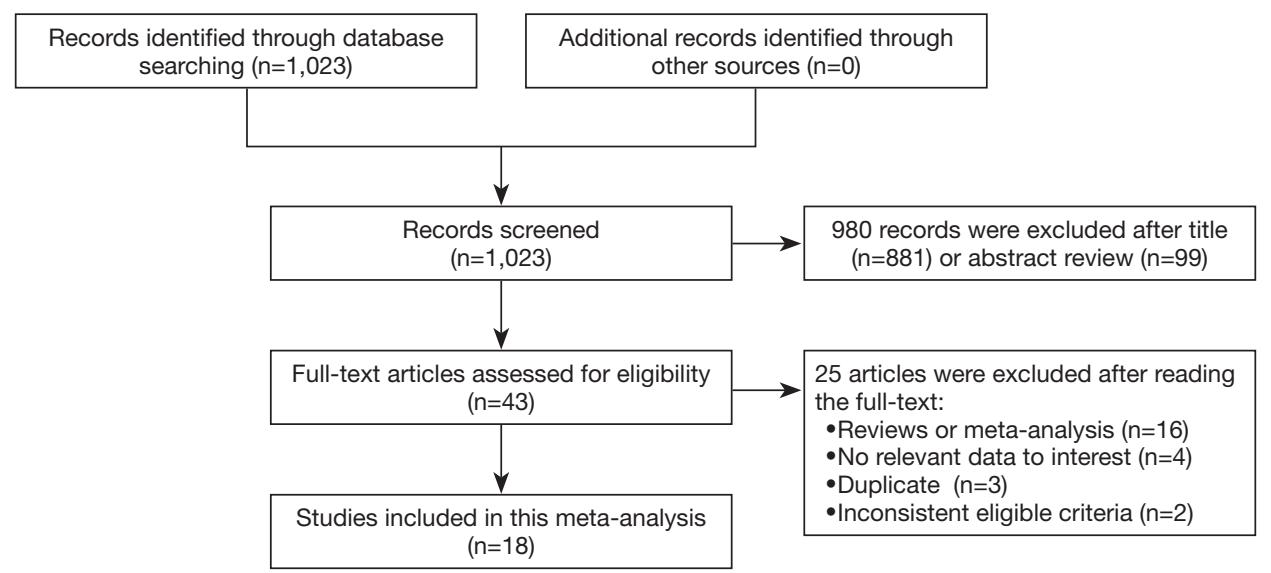

Figure 1 Flow chart of screening the eligible articles.

of participants into the study, in the classification of intervention, in deviations from intended interventions, in missing data in measurement of outcomes, and in selection of the reported result. Meanwhile, the Revised Cochrane Risk of Bias Tool (RoB2.0) was used for evaluating the bias of the RCTs. Publication bias was visually assessed by the symmetry of results on the funnel plots.

\section{Statistical analyses}

Stata 12.0 was used for statistical meta-analyses. The pooled odds ratios (ORs) and corresponding $95 \%$ confidence intervals (CIs) were calculated for the outcomes evaluating efficacy and safety of DOACs and LMWH in the treatment of VTE in cancer patients, and for subgroup analyses. Cochran's Q test and $\mathrm{I}^{2}$ statistic test were used for evaluating the heterogeneity of included studies. A $\mathrm{P}$ value $<0.01$ in the $\mathrm{Q}$ test or $\mathrm{I}^{2}$ value $>50 \%$ represented significant heterogeneity among the studies, and the random effects model was used for the meta-analysis; otherwise, the fixed effects model was used for pooled analysis.

\section{Results}

\section{Study characteristics}

A total of 1,023 articles were obtained after the initial retrieval with the relevant keywords. The flowchart for the selection of articles for final inclusion is illustrated in Figure 1. After screening according to the tittle and abstract, 43 articles were identified for comprehensive, full-text review. Among these, 16 articles were reviews, 4 articles lacked valid data, 3 articles reported the same population or were from the same institution, and 2 articles lacked a control group. Eventually, 18 articles were selected for final analyses, including 4 RCTs and 14 retrospective cohort studies, comprising a total of 7,319 cancer patients. Among these patients, 3,430 cases (46.9\%) and 3,889 cases (53.1\%) received DOAC and LMWH treatment, respectively. The characteristics results of the quality assessment of the included studies are shown in Tables S1,S2.

In terms of DOACs, 10 studies (including $1 \mathrm{RCT}$ ) compared the efficacy and safety of rivaroxaban and LMWH in the treatment of VTE (11-19), apixaban was used in 3 studies (including 2 RCTs) (19-21), edoxaban was given in 1 RCT (22), and 5 studies did not specify the oral anticoagulant used in the trials (23-27). The duration of follow-up these studies ranged from 6 months to 24 months.

\section{Efficacy of DOACs compared with LWMH in the treatment of VTE}

First, we investigated the pooled OR of DOACs compared with LWMHs for treatment of VTE in cancer patients. There was no significant heterogeneity among the included studies $\left(\mathrm{I}^{2}=0 \%, \mathrm{P}=0.921\right.$, Figure 2$)$, so the fixed effects model was used. The results of pooled analysis showed that DOACs significantly reduced the VTE recurrence in patients with cancer (OR: 0.68, 95\% CI: 0.57-0.8, P<0.001, Figure 2). Funnel plot did not show significant publication bias of these studies (Figure S1). The ORs for RCTs and retrospective studies were further calculated. Similarly, both RCTs and retrospective cohort studies confirmed a reduced risk of VTE recurrence in cancer patients (RCTs: OR, 0.60; 95\% 


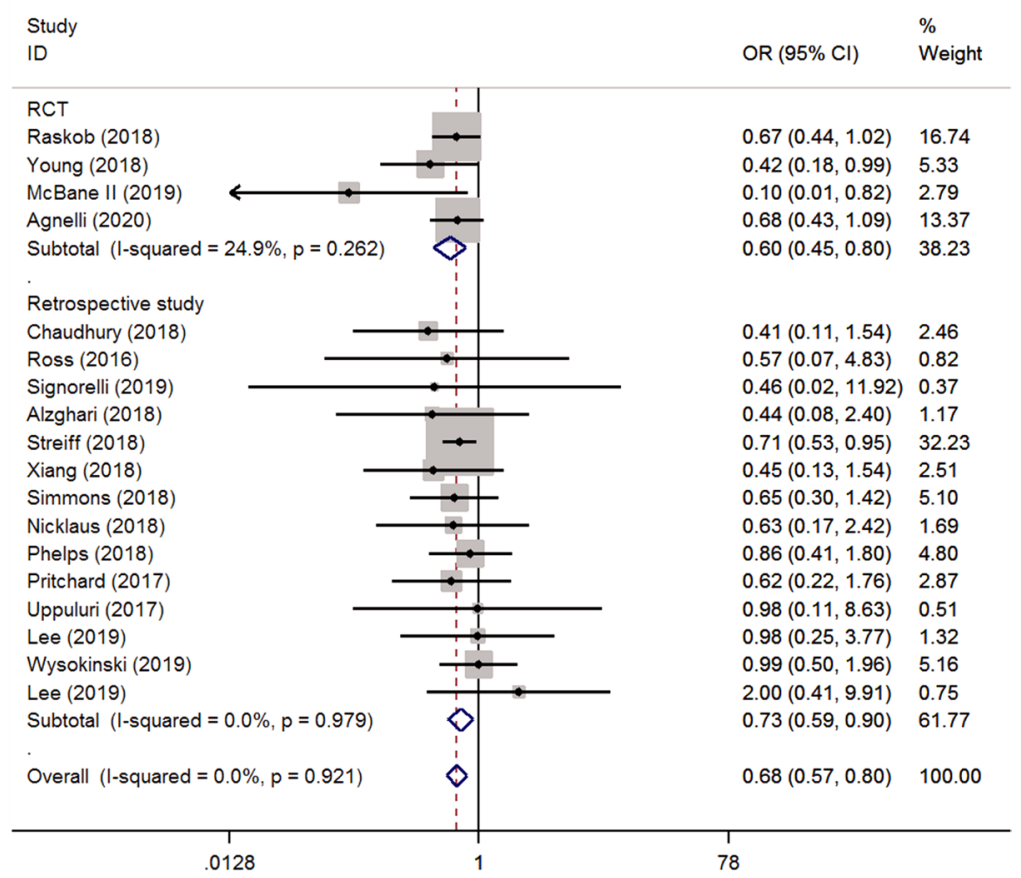

Figure 2 Forest plot of ORs of DOACs vs. LMWHs for VTE recurrence in RCTs and retrospective studies, respectively. OR, odds ratio; DOAC, direct oral anticoagulant; LMWH, low-molecular-weight heparin; VTE, venous thromboembolism; RCT, randomized controlled trial.

CI, 0.45-0.80; $\mathrm{P}<0.001$; heterogeneity, $\mathrm{I}^{2}=24.9 \%$; $\mathrm{P}=0.262$; retrospective studies: $\mathrm{OR}, 0.73$; 95\% CI, 0.59-0.90; $\mathrm{P}=0.003$; heterogeneity, $\mathrm{I}^{2}=0 \% ; \mathrm{P}=0.979$, Figure 2).

In order to clarify the efficacy of different DAOCs for VTE treatment, we further investigated the ORs for VTE recurrence of edoxaban, rivaroxaban, and apixaban. Interestingly, the results showed that only rivaroxaban was correlated with lower risk of VTE recurrence in cancer patients (OR, 0.69; 95\% CI, 0.54-0.87; $\mathrm{P}=0.002$; heterogeneity, $\mathrm{I}^{2}=0.0 \% ; \mathrm{P}=0.893$, Figure 3). These results confirmed that DOAC treatment, especially rivaroxaban, can significantly decrease the VTE recurrence risk in patients with cancer.

Second, the risk of DVT recurrence was compared between DOACs and LWMHs. A total of 9 studies evaluated the DVT recurrence risk in patients using DOACs or LWMHs. Pooled analysis showed a significantly decreased DVT recurrence in the DOAC group compared with that of the LWMH group (OR: 0.47, 95\% CI: 0.32 $0.67, \mathrm{P}<0.001$, heterogeneity, $\mathrm{I}^{2}=23.4 \% ; \mathrm{P}=0.236$, Figure 4). We did not find a significant publication bias of the included studies in the funnel plot (Figure S2). Consistently, RCTs and retrospective studies obtained similar results for DOACs (RCTs: OR, 0.54; 95\% CI, 0.36-0.80; $\mathrm{P}=0.002$; heterogeneity, $\mathrm{I}^{2}=16.5 \% ; \mathrm{P}=0.309$; retrospective studies: OR, 0.20; 95\% CI, 0.06-0.63; $\mathrm{P}=0.006$; heterogeneity, $\mathrm{I}^{2}$ $=34 \% ; \mathrm{P}=0.194$, Figure 4$)$.

Subgroup analysis revealed that only rivaroxaban was effective in reducing the DVT recurrence risk compared with LWMHs (OR: 0.31, 95\% CI: 0.14-0.66, P<0.001, heterogeneity, $\mathrm{I}^{2}=1.5 \% ; \mathrm{P}=0.362$, Figure 5). Only 1 study investigated the effect of edoxaban and LWMHs on DVT recurrence risk, and it was found that edoxaban reduced the risk of DVT recurrence in cancer patients (OR: 0.553, 95\% CI: 0.30-0.94, Figure 5). Another 2 studies found no significant relation between apixaban medication and reduced risk of DVT recurrence (OR: 0.62, 95\% CI: 0.311.24 , heterogeneity, $\mathrm{I}^{2}=65.5 \% ; \mathrm{P}=0.089$, Figure 5). Thus, these results confirmed that DOACs, especially rivaroxaban, can reduce the DVT recurrence risk in cancer patients.

Third, we conducted a meta-analysis on the effect of DOACs on PE recurrence. Results showed that the pooled OR and $95 \%$ CI for DOACs was $0.75(0.53,1.05)$, indicating that DOACs did not reduce the risk of $\mathrm{PE}$ recurrence compared with LMWHs (Heterogeneity, $\mathrm{I}^{2}=0.0 \% ; \mathrm{P}=0.664$, Figure 6). Funnel plot did not show a significant publication bias of the included studies (Figure S3). Consistent with the pooled analysis, subgroup analyses did not find a significant 


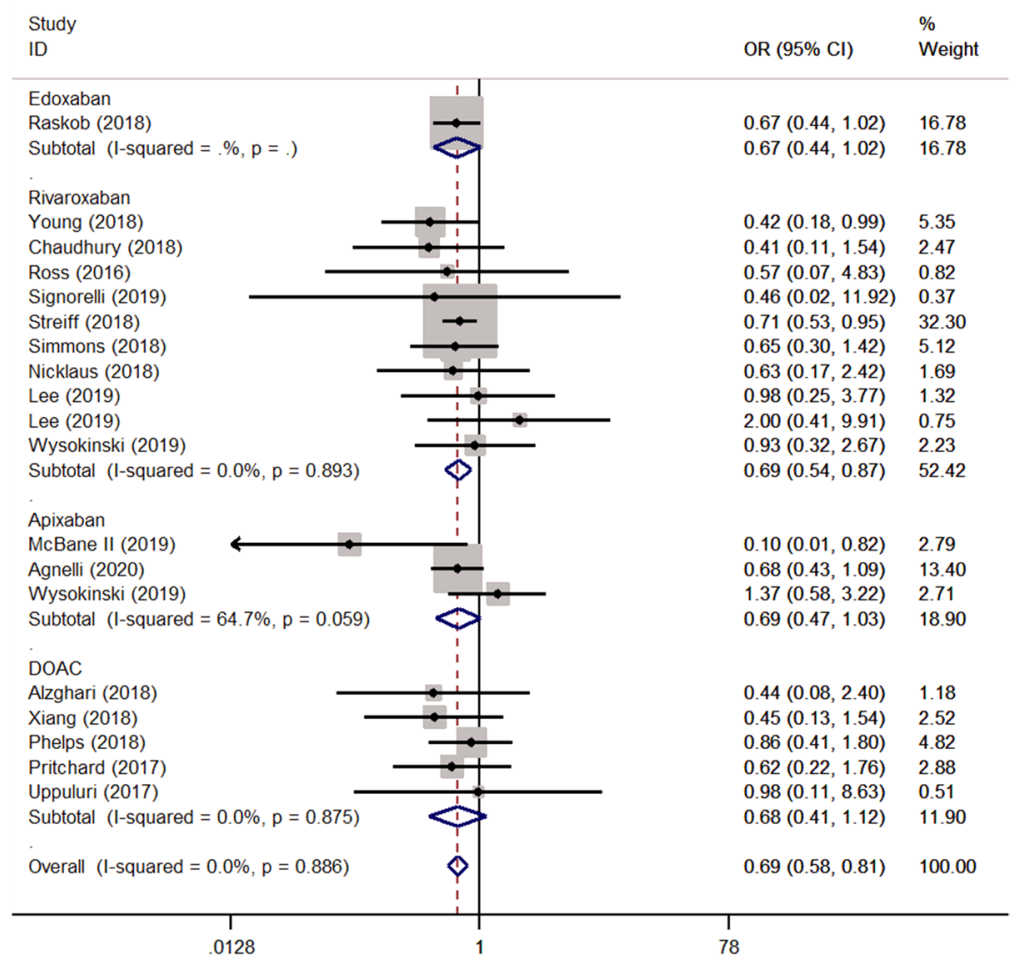

Figure 3 Subgroup analyses of ORs of different DOACs for VTE recurrence. OR, odds ratio; DOAC, direct oral anticoagulant; VTE, venous thromboembolism.

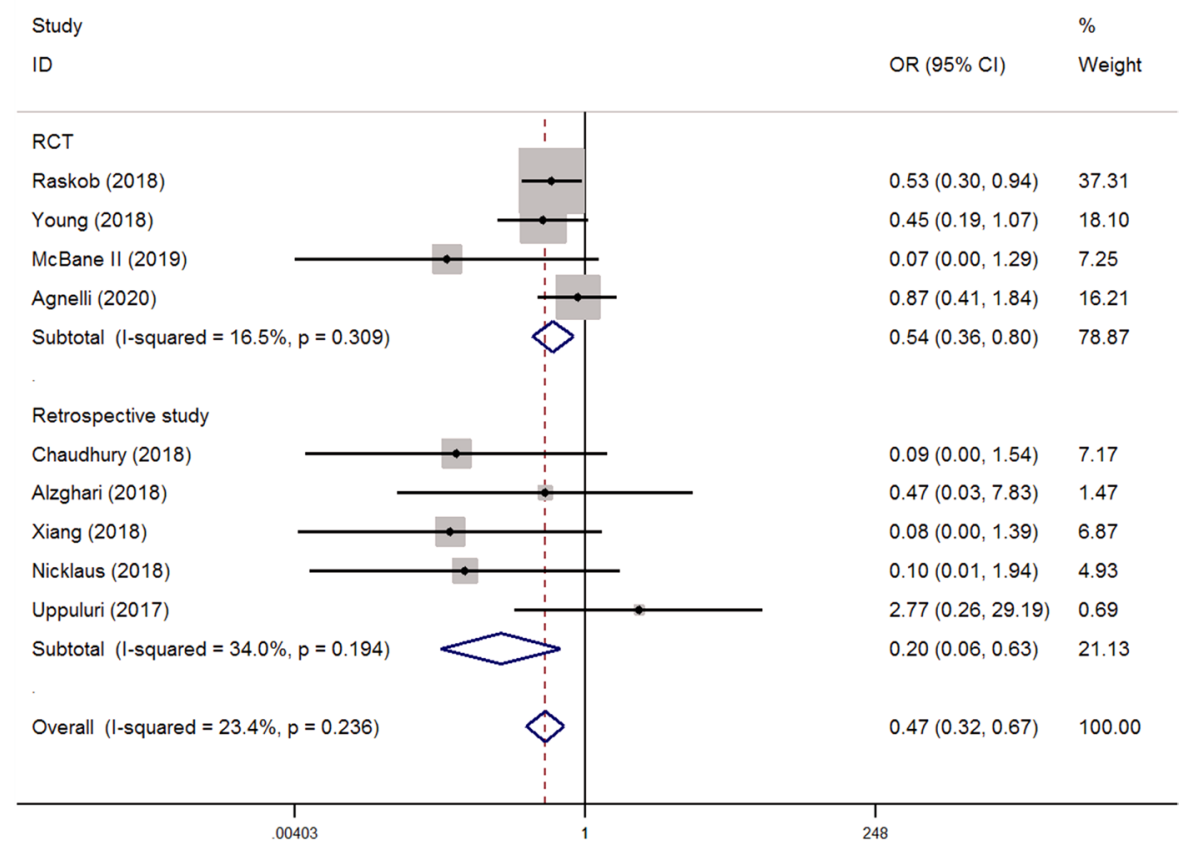

Figure 4 Forest plot of ORs of DOACs vs. LMWHs for DVT recurrence in RCTs and retrospective studies, respectively. OR, odds ratio; DOAC, direct oral anticoagulant; LMWH, low-molecular-weight heparin; DVT, deep vein thrombosis; RCT, randomized controlled trial. 


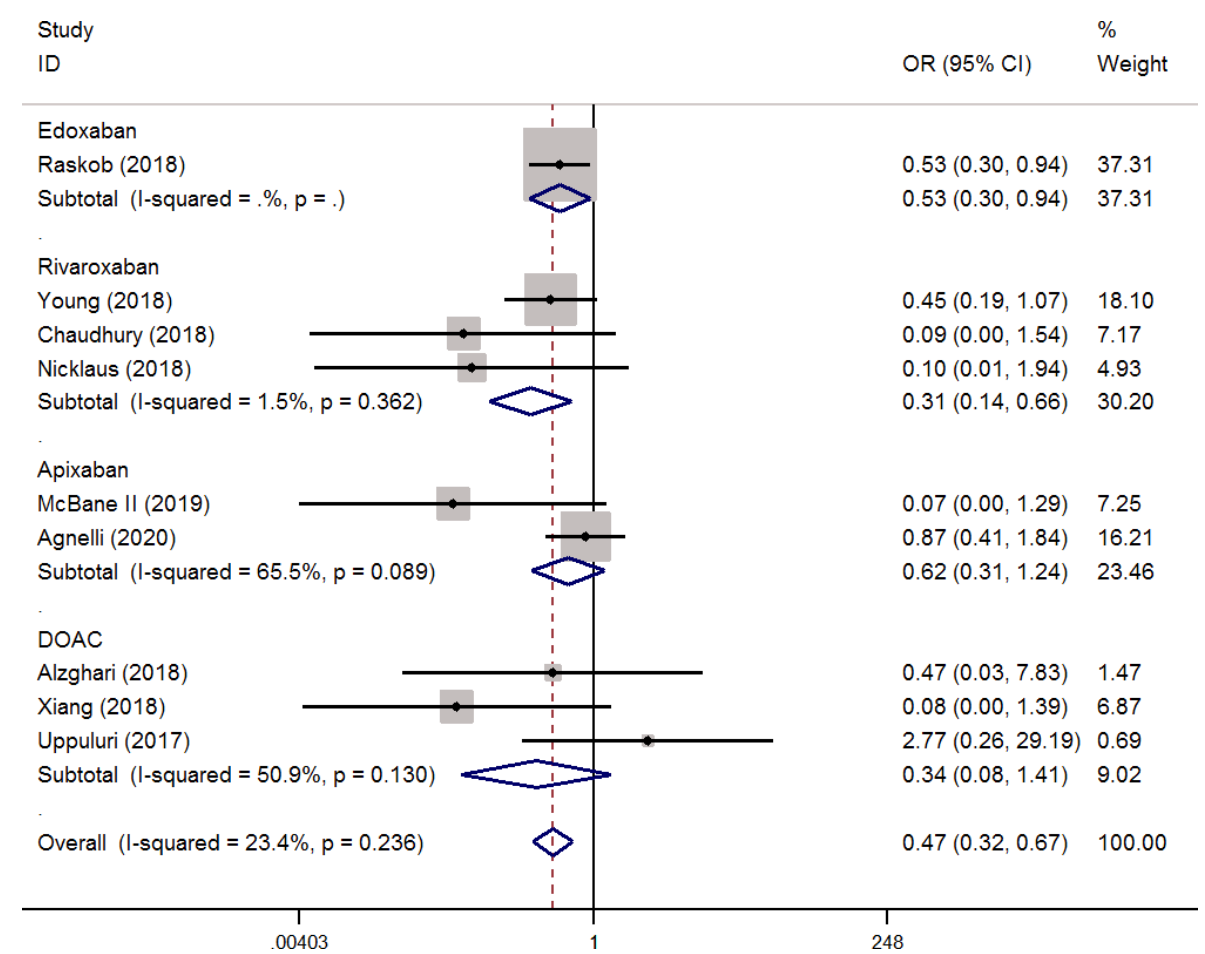

Figure 5 Subgroup analyses of ORs of different DOACs for DVT recurrence. OR, odds ratio; DOAC, direct oral anticoagulant; DVT, deep vein thrombosis.

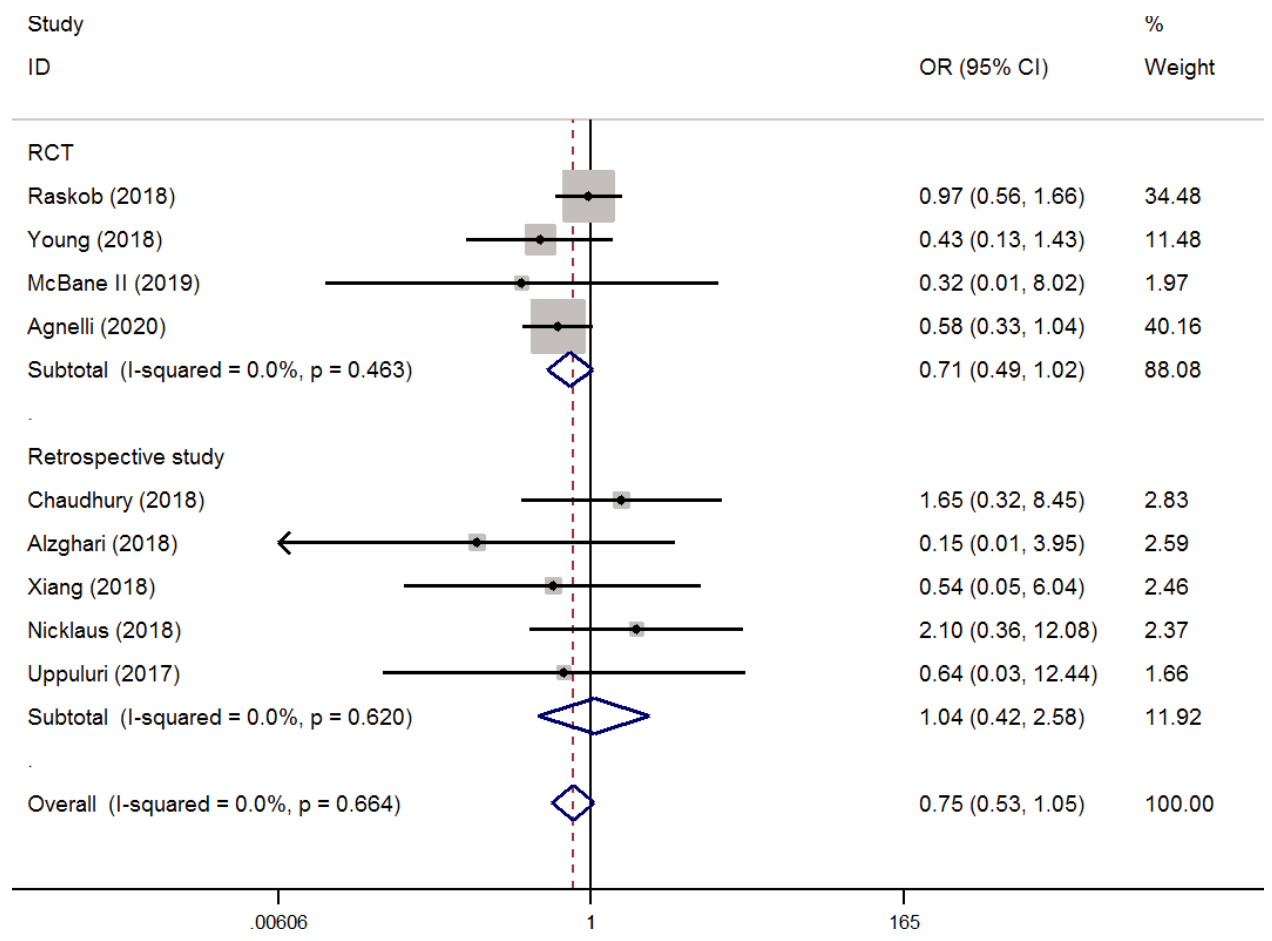

Figure 6 Forest plot of ORs of DOACs vs. LMWHs for PE recurrence in RCTs and retrospective studies, respectively. OR, odds ratio; DOAC, direct oral anticoagulant; LMWH, low-molecular-weight heparin; RCT, randomized controlled trial; PE, pulmonary embolism. 


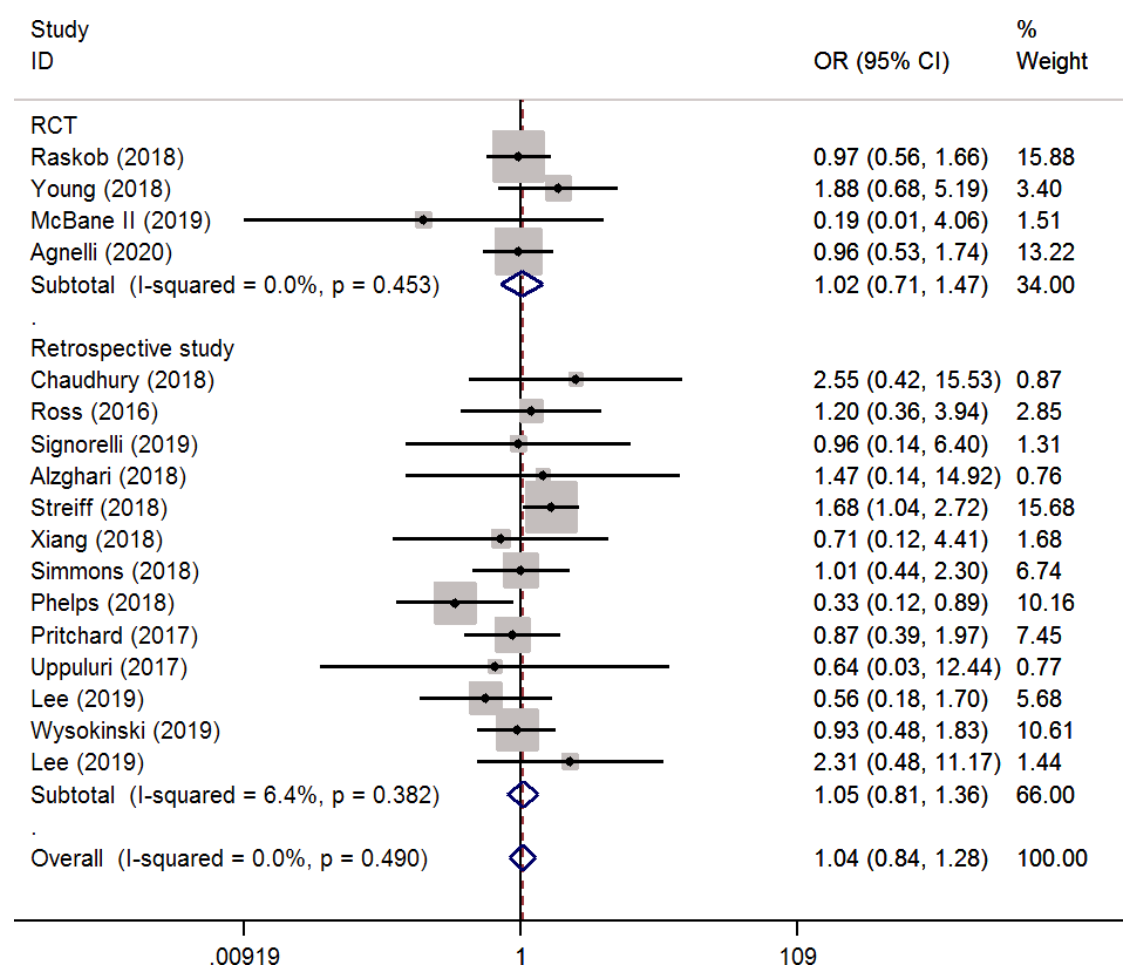

Figure 7 Forest plot of ORs of DOACs vs. LMWHs for major bleeding events in RCTs and retrospective studies, respectively. OR, odds ratio; DOAC, direct oral anticoagulant; LMWH, low-molecular-weight heparin; RCT, randomized controlled trial.

difference in PE recurrence risk between LMWHs and edoxaban, rivaroxaban, or apixaban (Figure S4). In addition, there was no significant difference in fatal PE recurrence between DOACs and LMWHs in cancer patients (Figure S5).

\section{Safety of DOACs compared with LWMHs}

In order to evaluate the safety of DOACs compared with LWMHs, we investigated the occurrence of major bleeding events and CRNMB events in the treatment of VTE. Pooled analysis showed that DOACs did not increase the risk of major bleeding events in cancer patients (OR: 1.04, 95\% CI: $0.84-1.28$, heterogeneity, $\mathrm{I}^{2}=0.0 \% ; \mathrm{P}=0.490$, Figure 7). We did not find a significant publication bias of the included studies (Figure S6). However, subgroup analysis revealed an increased risk of major bleeding events in the rivaroxaban group compared with the LMWH group (OR: 1.36, 95\% CI: 1.01-1.82, heterogeneity, $\mathrm{I}^{2}=0.0 \%$; $\mathrm{P}=0.714$, Figure 8).

Finally, we found that DOACs significantly increased the risk of CRNMB in cancer patients (OR: 1.45, 95\% CI: 1.21-1.73, heterogeneity, $\mathrm{I}^{2}=48.3 \% ; \mathrm{P}=0.022$, Figure 9), and a similar result was found in the RCTs (OR: 1.58, 95\% CI: $1.22-2.04$, heterogeneity, $\mathrm{I}^{2}=42.3 \% ; \mathrm{P}=0.158$, Figure 9) and retrospective studies (OR: 1.33, 95\% CI: 1.03-1.70, heterogeneity, $\mathrm{I}^{2}=53.6 \% ; \mathrm{P}=0.022$, Figure 9). No significant publication bias of the included studies was observed on the funnel plot (Figure S7). Subgroup analysis confirmed that the increase of CRNMB events was only observed in the rivaroxaban group compared with the LMWH group (OR: 2.41, 95\% CI: $1.75-3.31$, heterogeneity, $\mathrm{I}^{2}=0.0 \% ; \mathrm{P}=0.467$, Figure 10).

\section{Discussion}

In this study, the pooled results of meta-analysis showed that DOACs significantly reduced the occurrence of recurrent VTE and DVT, but not PE or fatal PE, compared with LMWHs in patients with cancer. Subgroup analyses revealed the substantive efficacy of rivaroxaban in decreasing the VTE and DVT recurrence. In addition, DOACs did not increase the risk of major bleeding events, but the risk of CRNMBs were increased. Subgroup analyses confirmed the role of rivaroxaban in increasing the risk of major bleeding events and CRNMBs. 


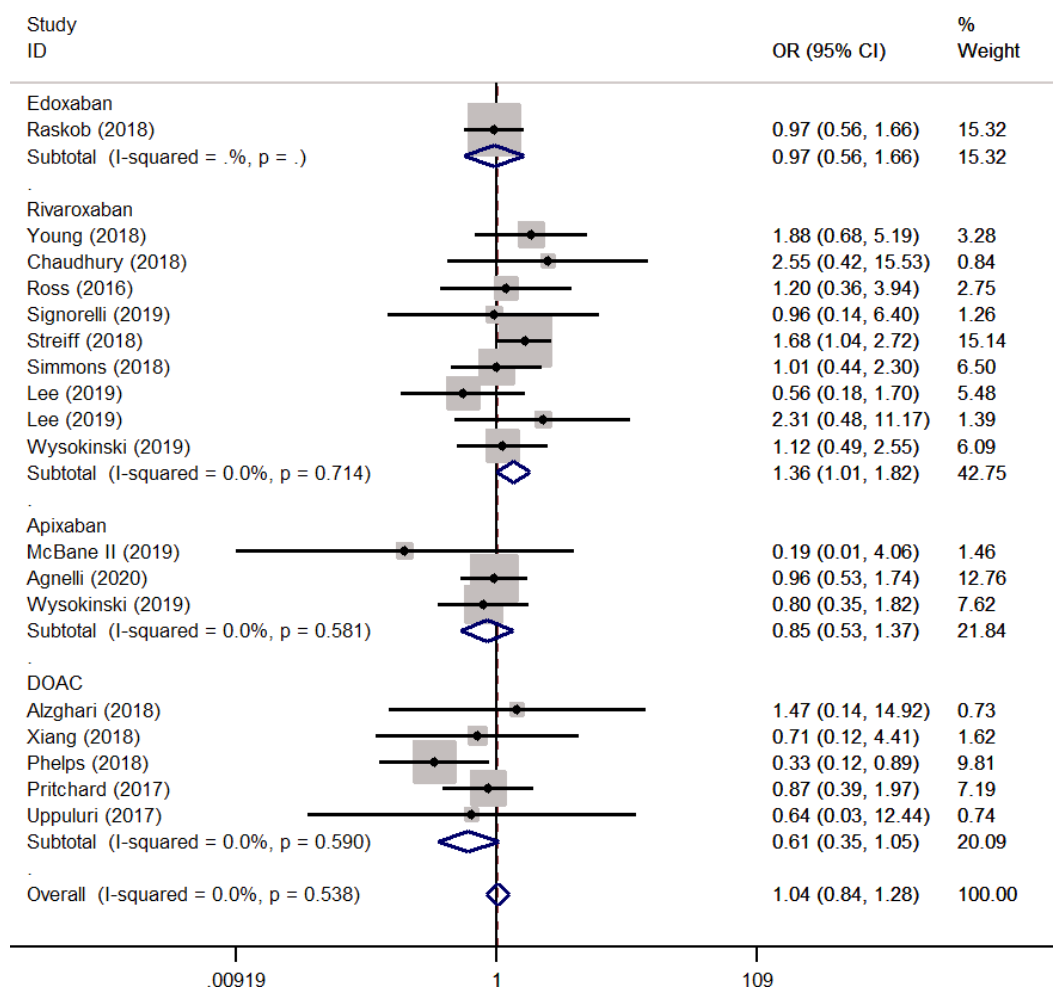

Figure 8 Subgroup analyses of ORs of different DOACs for major bleeding events. OR, odds ratio; DOAC, direct oral anticoagulant.

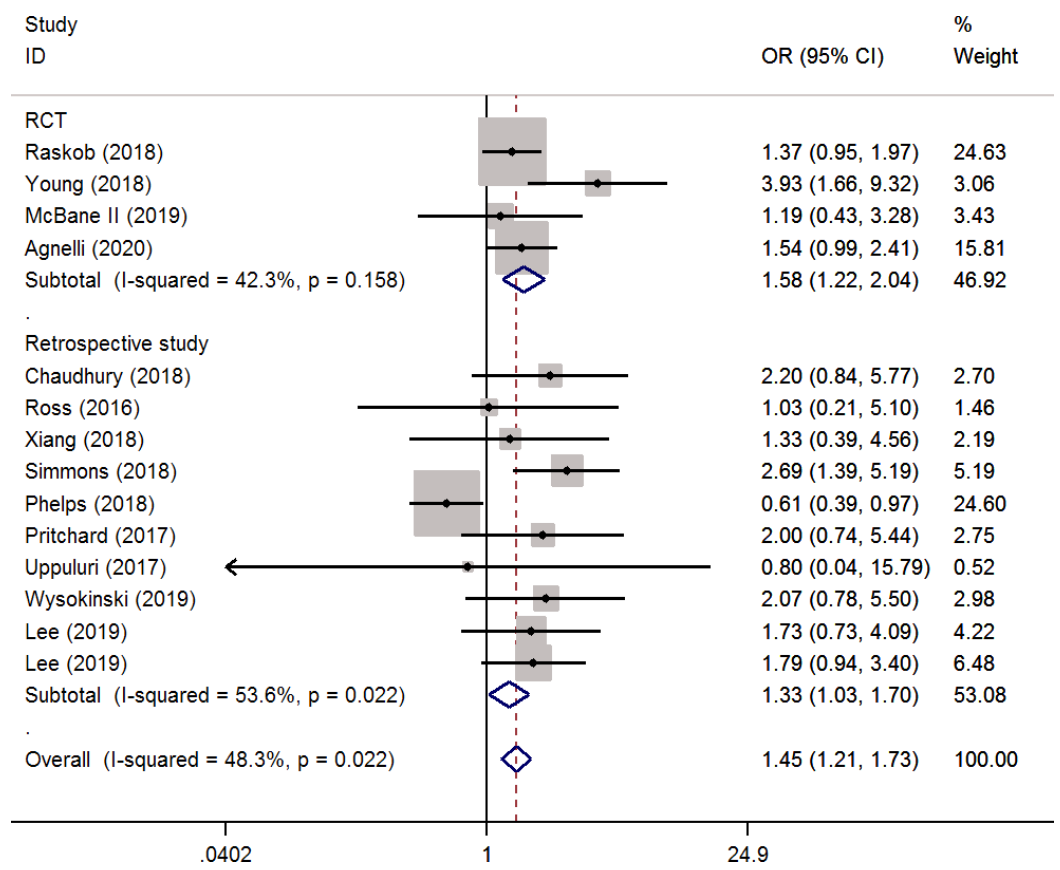

Figure 9 Forest plot of ORs of DOACs vs. LMWHs for CRNMBs in RCTs and retrospective studies, respectively. OR, odds ratio; DOAC, direct oral anticoagulant; LMWH, low-molecular-weight heparin; CRNMB, clinically relevant non-major bleeding; RCT, randomized controlled trial. 


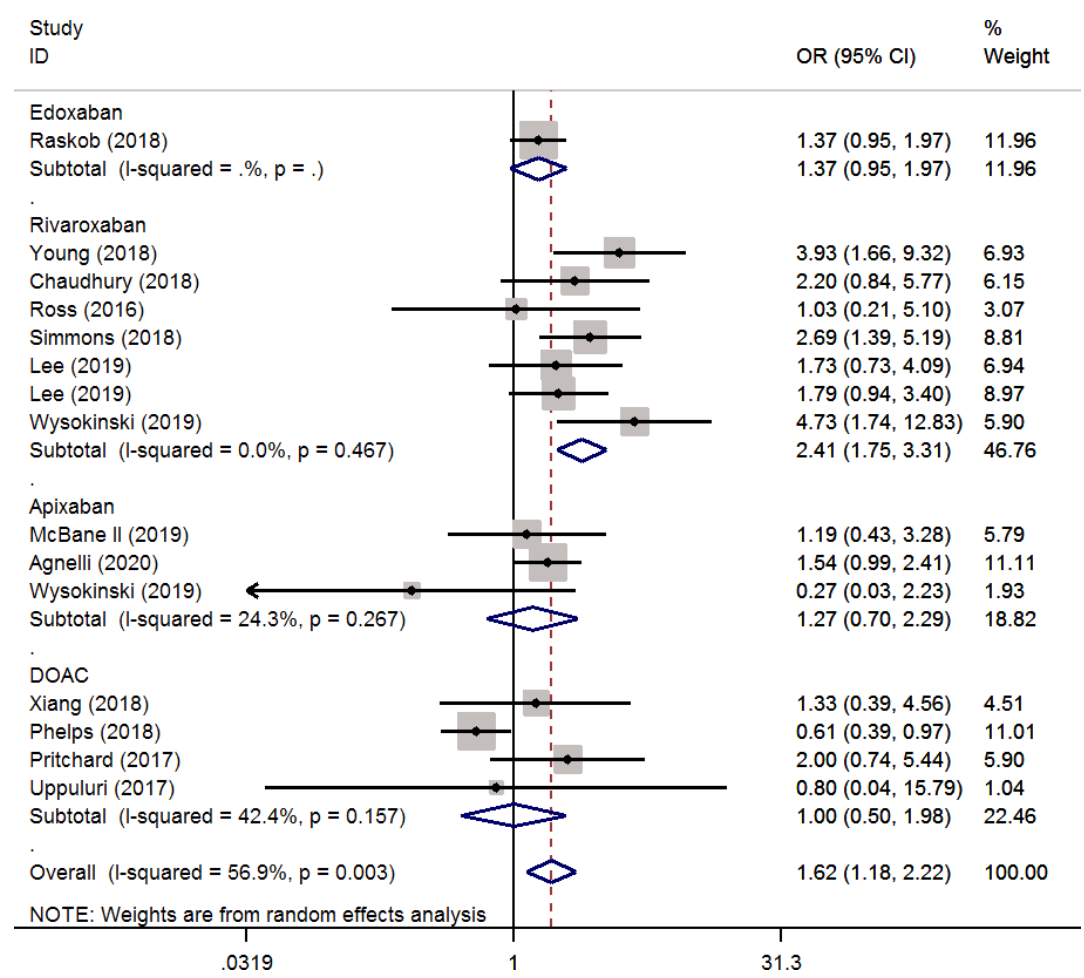

Figure 10 Subgroup analyses of ORs of different DOACs for CRNMBs. OR, odds ratio; DOAC, direct oral anticoagulant; CRNMB, clinically relevant non-major bleeding.

Anticoagulant therapy is a complex clinical issue in cancer patients as it can provide a balance between anticoagulation and bleeding. Traditionally, LMWHs are the preferred drugs for anticoagulant therapy in the prophylaxis and treatment of VTE, and have been recommended by many guidelines (4). It has been well established that LMWHs are effective in reducing VTE and overall mortality (28), although the risk of bleeding is still disputed (4). In recent years, the role of DOACs in the treatment of cancerassociated VTE has been increasingly recognized. A series of reviews and meta-analyses showed that DOACs were better than LMWHs in preventing recurrent VTE in cancer patients $(29,30)$. Similarly, DOACs were found to be effective in reducing DVT recurrence $(9,31)$, but not $\mathrm{PE}$ recurrence (31). Inconsistent with these results, we confirmed in our meta-analysis that the risk of VTE and DVT recurrence was significantly lower in patients treated with DOACs than in those treated with LMWHs. However, there was no significant difference in the risk of recurrent $\mathrm{PE}$ or fatal $\mathrm{PE}$ between the 2 groups.

Since DOACs include rivaroxaban, edoxaban, apixaban, and other drugs, we further analyzed the risk effects of different kinds of DOACs in cancer patients by subgroup analyses. One RCT compared the efficacy of edoxaban with LMWH (22), but no significant difference in VTE recurrence was detected. Ten studies $(1,9,12-16,18,19)$ including one RCT (11) investigated the risk of recurrent VTE in patients receiving rivaroxaban compared with LMWH. The incidence of VTE recurrence was significantly lower in the rivaroxaban group, suggesting rivaroxaban's relatively positive effect in reducing recurrent VTE compared with LMWH. After excluding the RCT in meta-analysis, the difference in VTE recurrence between the 2 groups was still significant, further confirming the association between lower VTE risk and rivaroxaban treatment. Two RCTs $(20,21)$ and one retrospective study (19) compared the effect of apixaban with LMWH, and no significant OR for apixaban in VTE risk was found. However, when we excluded the retrospective study, the pooled analysis of the 2 RCTs did demonstrate a lower VTE risk in patients with apixaban. Therefore, more RCTs are needed to further confirm the role of apixaban in preventing VTE recurrence in cancer patients.

DVT events and PE events are the main manifestations 


\section{Page 10 of 12}

of VTE in patients with cancer. Our study found that DOACs were superior to LMWHs in preventing recurrent DVT, which was consistent with previous studies $(9,31)$. Subgroup analyses were performed in the edoxaban, rivaroxaban, and apixaban groups based on the available data. Only 1 RCT (22) investigated the difference in DVT recurrence between edoxaban and $\mathrm{LMWH}$ treatment and results showed a lower risk of recurrent DVT in patients receiving edoxaban. One RCT (11) and two retrospective studies $(12,14)$ compared the efficacy of rivaroxaban and LMWHs, and the results demonstrated that rivaroxaban significantly reduced the DVT recurrence in cancer patients. Two RCTs $(20,21)$ on apixaban found that it had no effect on reducing the DVT recurrence compared with LMWHs. Moreover, pooled and subgroup analyses of the included studies did not attest to the superior efficacy of DOACs - in any of edoxaban, rivaroxaban, or apixabanover LMWHs to reduce the risk of recurrent PE and fatal PE. Despite to the limited amount of data, these results indicated that rivaroxaban may be particularly important in reducing the risk of VTE recurrence in cancer patients. Further studies are still needed to clarify the role of the other DOACs in the treatment of patients with cancer.

Currently, findings concerning the effect of DOACs on major bleeding events in cancer patients are conflicting. Some studies have found that DOACs increase the risk of major bleeding (9), while other studies did not report such an elevated risk (31). In our pooled analysis of either the RCTs or retrospective studies, there was no significant difference in the occurrence of major bleeding events between DOACs and LMWHs. However, subgroup analyses showed that rivaroxaban did increase the major bleeding events in cancer patients while edoxaban and apixaban did not induce an elevated risk of major bleeding events. Thus, it is important for clinicians to consider the characteristics of different DOACs in patients with cancer. Consistent with previous studies $(9,31)$, our analysis confirmed that DOACs increased the risk of CRNMBs, suggesting a tendency of DOACs to promote bleeding. However, 1 RCT on edoxaban found that the CRNMBs risk was not increased after treatment (22). Two RCTs $(20,21)$ and one retrospective study (19) consistently showed that apixaban did not increase the risk of CRNMB events in patients with cancer. Therefore, edoxaban and apixaban may be safer than rivaroxaban in the treatment of VTE in cancer patients.

Some limitations to this study should be addressed. First, due to the limited data on different kinds of DOACs,

\section{Song et al. DOACs for the treatment of venous thromboembolism}

studies comparing edoxaban, apixaban, and LMWHs are rare. Thus, the conclusions in this study still needed to be further confirmed by a larger collection of data. Second, the number of RCTs for different DOACs is somewhat small, with only 1 or 2 RCTs being included in the meta-analysis. Multicenter RCTs with a large sample size are needed to further investigate the efficacy and safety of specific DOACs. Third, the subgroups of different kinds of cancers were not analyzed, but influence the efficacy and safety of different DOACs may vary depending on cancer type (31). Future studies should focus on the effects of different DOACs on specific cancers so as to help clinicians better determine the treatment strategy for VTE in patients with different cancers.

\section{Acknowledgments}

Funding: None.

\section{Footnote}

Reporting Checklist: The authors have completed the PRISMA reporting checklist. Available at http://dx.doi. org/10.21037/atm-20-8156

Conflicts of Interest: All authors have completed the ICMJE uniform disclosure form (available at http://dx.doi. org/10.21037/atm-20-8156). The authors have no conflicts of interest to declare.

Ethical Statement: The authors are accountable for all aspects of the work in ensuring that questions related to the accuracy or integrity of any part of the work are appropriately investigated and resolved.

Open Access Statement: This is an Open Access article distributed in accordance with the Creative Commons Attribution-NonCommercial-NoDerivs 4.0 International License (CC BY-NC-ND 4.0), which permits the noncommercial replication and distribution of the article with the strict proviso that no changes or edits are made and the original work is properly cited (including links to both the formal publication through the relevant DOI and the license). See: https://creativecommons.org/licenses/by-nc-nd/4.0/.

\section{References}

1. Timp JF, Braekkan SK, Versteeg HH, et al. Epidemiology 
of cancer-associated venous thrombosis. Blood 2013;122:1712-23.

2. Cohen AT, Katholing A, Rietbrock S, et al. Epidemiology of first and recurrent venous thromboembolism in patients with active cancer. A population-based cohort study. Thromb Haemost 2017;117:57-65.

3. Geerts WH, Bergqvist D, Pineo GF, et al. Prevention of venous thromboembolism: American College of Chest Physicians Evidence-Based Clinical Practice Guidelines (8th Edition). Chest 2008;133:381S-453S.

4. Farge D, Bounameaux H, Brenner B, et al. International clinical practice guidelines including guidance for direct oral anticoagulants in the treatment and prophylaxis of venous thromboembolism in patients with cancer. Lancet Oncol 2016;17:e452-66.

5. Kamphuisen PW, Beyer-Westendorf J. Bleeding complications during anticoagulant treatment in patients with cancer. Thromb Res 2014;133 Suppl 2:S49-55.

6. Kearon C, Akl EA, Ornelas J, et al. Antithrombotic Therapy for VTE Disease: CHEST Guideline and Expert Panel Report. Chest 2016;149:315-52.

7. Song AB, Rosovsky RP, Connors JM, et al. Direct oral anticoagulants for treatment and prevention of venous thromboembolism in cancer patients. Vasc Health Risk Manag 2019;15:175-86.

8. Franco-Moreno A, Cabezon-Gutierrez L, Palka-Kotlowsa M, et al. Evaluation of direct oral anticoagulants for the treatment of cancer-associated thrombosis: an update. J Thromb Thrombolysis 2019;47:409-19.

9. Li A, Garcia DA, Lyman GH, et al. Direct oral anticoagulant (DOAC) versus low-molecular-weight heparin $(\mathrm{LMWH})$ for treatment of cancer associated thrombosis (CAT): A systematic review and meta-analysis. Thromb Res 2019;173:158-63.

10. Moher D, Shamseer L, Clarke M, et al. Preferred reporting items for systematic review and meta-analysis protocols (PRISMA-P) 2015 statement. Syst Rev 2015;4:1.

11. Young AM, Marshall A, Thirlwall J, et al. Comparison of an Oral Factor Xa Inhibitor With Low Molecular Weight Heparin in Patients With Cancer With Venous Thromboembolism: Results of a Randomized Trial (SELECT-D). J Clin Oncol 2018;36:2017-23.

12. Chaudhury A, Balakrishnan A, Thai C, et al. The Efficacy and Safety of Rivaroxaban and Dalteparin in the Treatment of Cancer Associated Venous Thrombosis. Indian J Hematol Blood Transfus 2018;34:530-4.

13. Signorelli JR, Gandhi AS. Evaluation of rivaroxaban use in patients with gynecologic malignancies at an academic medical center: A pilot study. J Oncol Pharm Pract 2019;25:362-8.

14. Nicklaus MD, Ludwig SL, Kettle JK. Recurrence of malignancy-associated venous thromboembolism among patients treated with rivaroxaban compared to enoxaparin. J Oncol Pharm Pract 2018;24:185-9.

15. Simmons B, Wysokinski W, Saadiq RA, et al. Efficacy and safety of rivaroxaban compared to enoxaparin in treatment of cancer-associated venous thromboembolism. Eur J Haematol 2018. [Epub ahead of print]. doi: 10.1111/ ejh.13074.

16. Streiff MB, Milentijevic D, McCrae K, et al. Effectiveness and safety of anticoagulants for the treatment of venous thromboembolism in patients with cancer. Am J Hematol 2018;93:664-71.

17. Lee JH, Oh YM, Lee SD, et al. Rivaroxaban versus LowMolecular-Weight Heparin for Venous Thromboembolism in Gastrointestinal and Pancreatobiliary Cancer. J Korean Med Sci 2019;34:e160.

18. Lee JH, Hyun DG, Choi CM, et al. A Retrospective Study on Efficacy and Safety of Rivaroxaban and Dalteparin for Long-Term Treatment of Venous Thromboembolism in Patients with Lung Cancer. Respiration 2019;98:203-11.

19. Wysokinski WE, Houghton DE, Casanegra AI, et al. Comparison of apixaban to rivaroxaban and enoxaparin in acute cancer-associated venous thromboembolism. Am J Hematol 2019;94:1185-92.

20. McBane RD, 2nd, Wysokinski WE, Le-Rademacher JG, et al. Apixaban and dalteparin in active malignancyassociated venous thromboembolism: The ADAM VTE trial. J Thromb Haemost 2020;18:411-21.

21. Agnelli G, Becattini C, Meyer G, et al. Apixaban for the Treatment of Venous Thromboembolism Associated with Cancer. N Engl J Med 2020;382:1599-607.

22. Raskob GE, van Es N, Verhamme P, et al. Edoxaban for the Treatment of Cancer-Associated Venous Thromboembolism. N Engl J Med 2018;378:615-24.

23. Alzghari SK, Seago SE, Garza JE, et al. Retrospective comparison of low molecular weight heparin vs. warfarin vs. oral Xa inhibitors for the prevention of recurrent venous thromboembolism in oncology patients: The ReCLOT study. J Oncol Pharm Pract 2018;24:494-500.

24. Xiang E, Ahuja T, Raco V, et al. Anticoagulation prescribing patterns in patients with cancer. J Thromb Thrombolysis 2018;45:89-98.

25. Phelps MK, Wiczer TE, Erdeljac HP, et al. A single center retrospective cohort study comparing low-molecularweight heparins to direct oral anticoagulants for the 
Page 12 of 12

treatment of venous thromboembolism in patients with cancer - A real world experience. J Oncol Pharm Pract 2019;25:793-800.

26. Uppuluri EM, Burke KR, Haaf CM, et al. Assessment of venous thromboembolism treatment in patients with cancer on low molecular weight heparin, warfarin, and the direct oral anticoagulants. J Oncol Pharm Pract 2019;25:261-8.

27. Pritchard ER, Murillo JR, Jr., Putney D, et al. Singlecenter, retrospective evaluation of safety and efficacy of direct oral anticoagulants versus low-molecular-weight heparin and vitamin $\mathrm{K}$ antagonist in patients with cancer. J Oncol Pharm Pract 2019;25:52-9.

28. Akl EA, Kahale L, Neumann I, et al. Anticoagulation for the initial treatment of venous thromboembolism in patients with cancer. Cochrane Database Syst Rev

Cite this article as: Song $\mathrm{X}$, Liu Z, Zeng R, Shao J, Liu B, Zheng Y, Liu C, Ye W. Treatment of venous thromboembolism in cancer patients: a systematic review and meta-analysis on the efficacy and safety of different direct oral anticoagulants (DOACs). Ann Transl Med 2021;9(2):162. doi: 10.21037/atm20-8156
Song et al. DOACs for the treatment of venous thromboembolism

2014;(4):CD006649.

29. Rossel A, Robert-Ebadi H, Combescure C, et al. Anticoagulant therapy for acute venous thrombo-embolism in cancer patients: A systematic review and network metaanalysis. PLoS One 2019;14:e0213940.

30. Sobieraj DM, Baker WL, Smith E, et al. Anticoagulation for the Treatment of Cancer-Associated Thrombosis: A Systematic Review and Network Meta-Analysis of Randomized Trials. Clin Appl Thromb Hemost 2018;24:182S-7S.

31. Haykal T, Zayed Y, Deliwala S, et al. Direct oral anticoagulant versus low-molecular-weight heparin for treatment of venous thromboembolism in cancer patients: An updated meta-analysis of randomized controlled trials. Thromb Res 2020;194:57-65. 


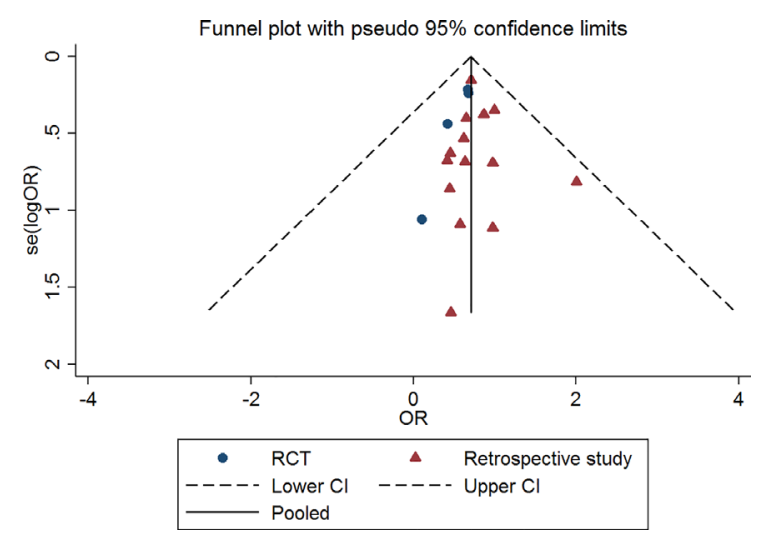

Figure S1 Funnel plot for the evaluation of publication bias of studies comparing DOACs and LWMHs for the treatment of VTE recurrence in cancer patients. DOAC, direct oral anticoagulant; LMWH, low-molecular-weight heparin; VTE, venous thromboembolism.

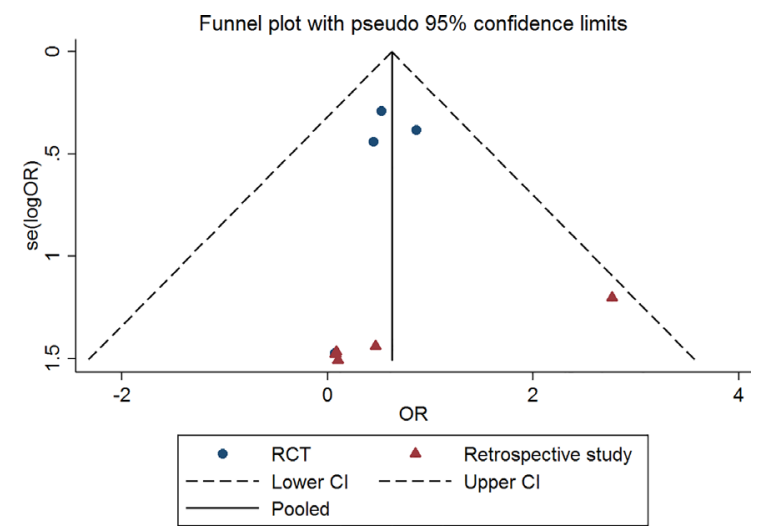

Figure S2 Funnel plot for the evaluation of publication bias of studies comparing DOACs and LWMHs for the treatment of DVT recurrence in cancer patients. DOAC, direct oral anticoagulant; LMWH, low-molecular-weight heparin; DVT, deep vein thrombosis.

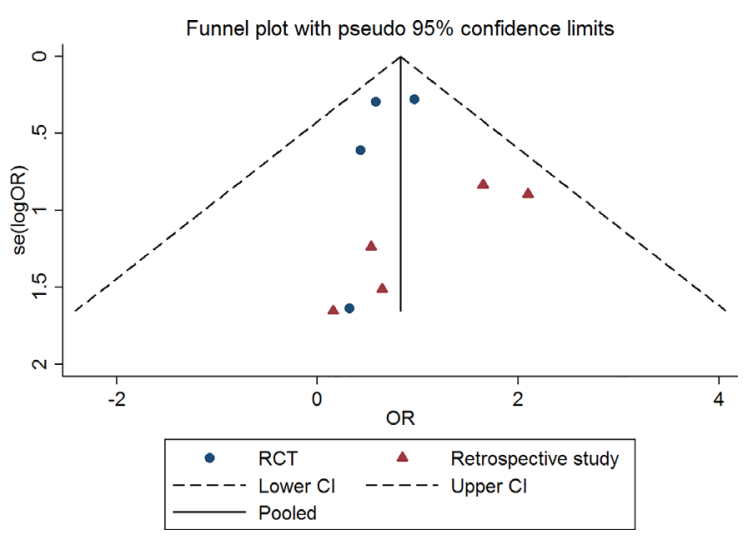

Figure S3 Funnel plot for the evaluation of publication bias of studies comparing DOACs and LWMHs for the treatment of PE recurrence in cancer patients. DOAC, direct oral anticoagulant; LMWH, low-molecular-weight heparin; PE, pulmonary embolism. 


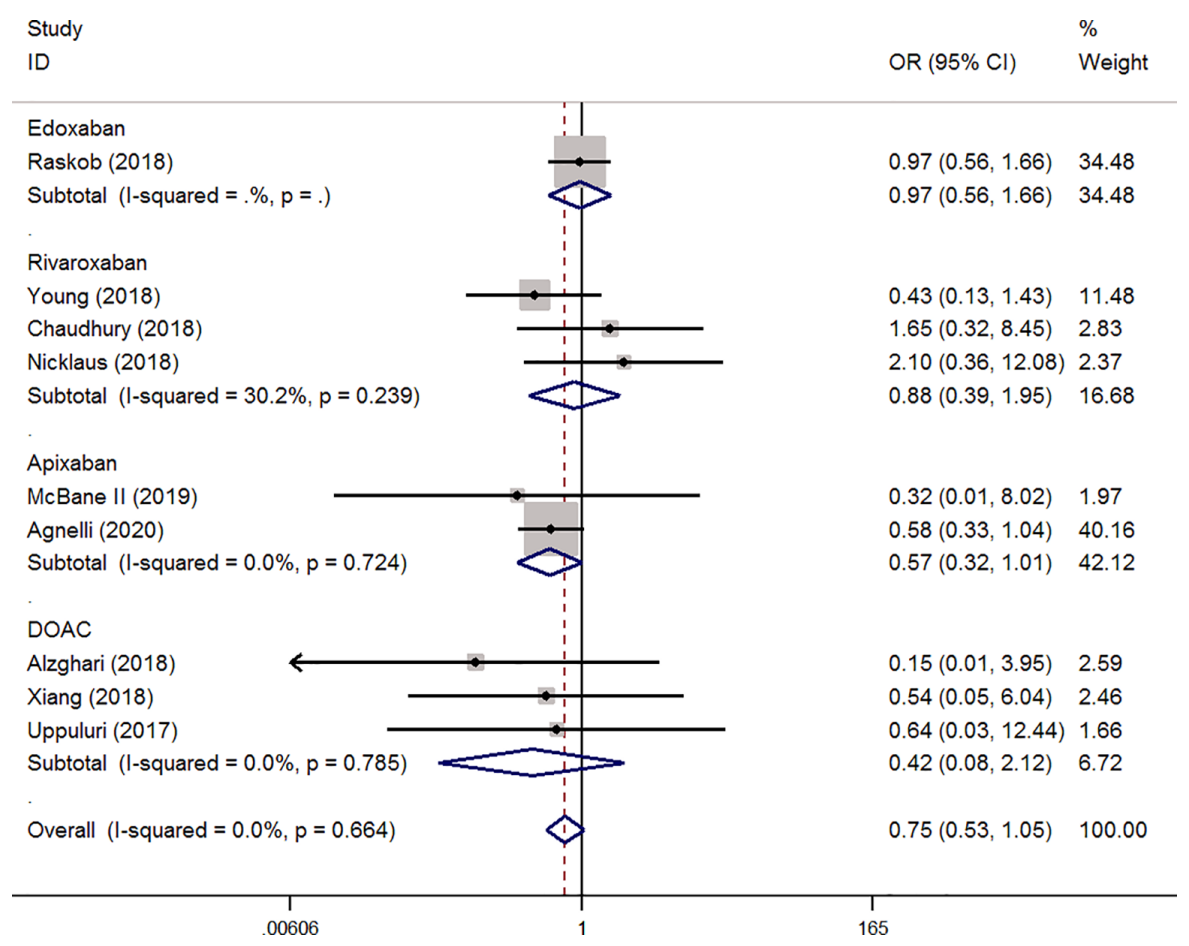

Figure S4 Subgroup analyses of ORs of different DOACs for PE recurrence. OR, odds ratio; DOAC, direct oral anticoagulant; PE, pulmonary embolism.

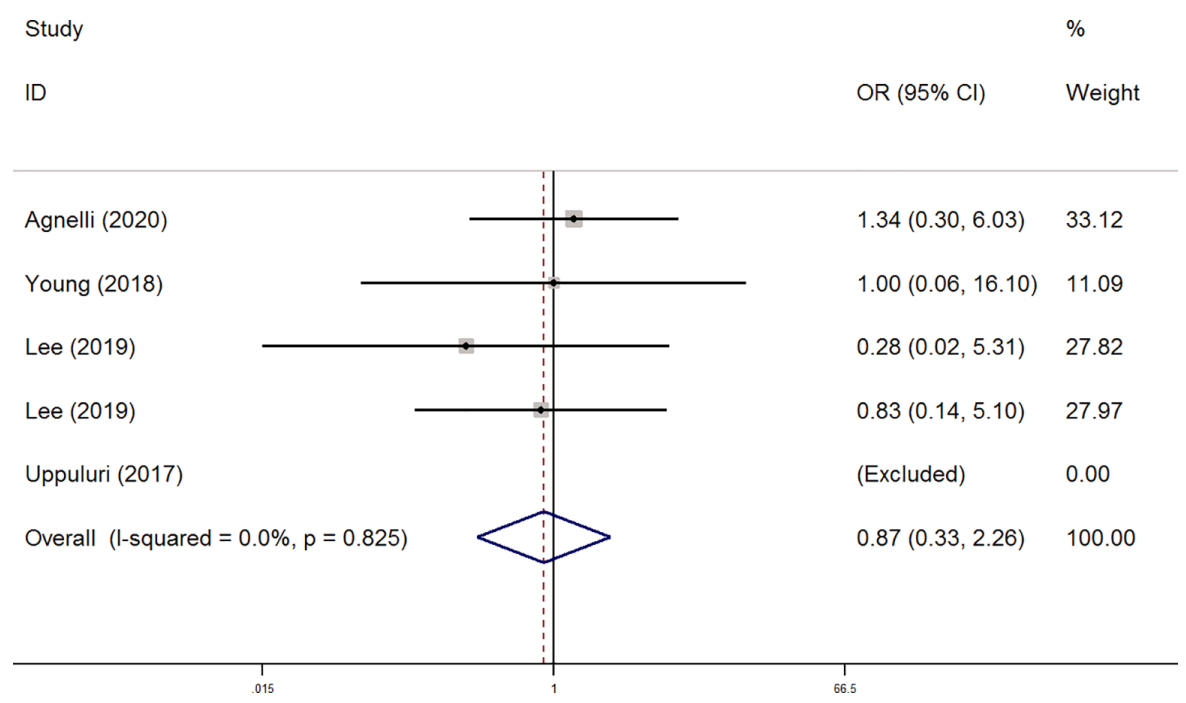

Figure S5 Forest plot of ORs of DOACs vs. LMWHs for fatal PE recurrence. OR, odds ratio; DOAC, direct oral anticoagulant; LMWH, low-molecular-weight heparin; PE, pulmonary embolism. 


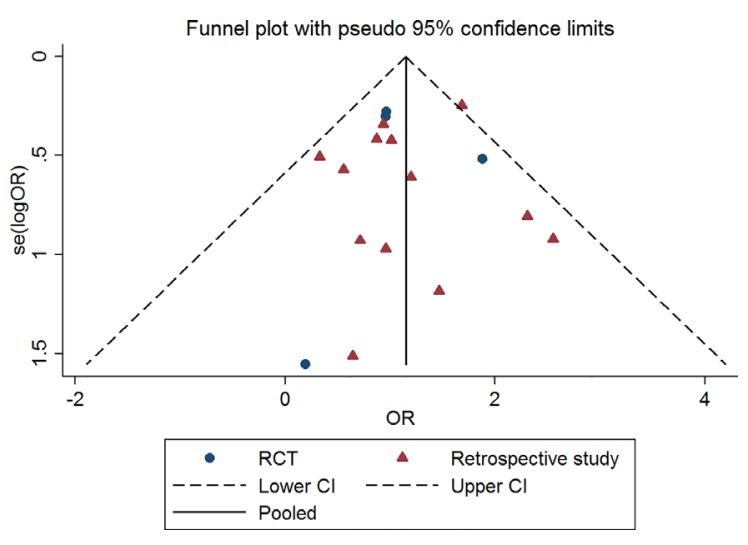

Figure S6 Funnel plot for the evaluation of publication bias of studies comparing DOACs and LWMHs for the major bleeding events in cancer patients. DOAC, direct oral anticoagulant; LMWH, low-molecular-weight heparin.

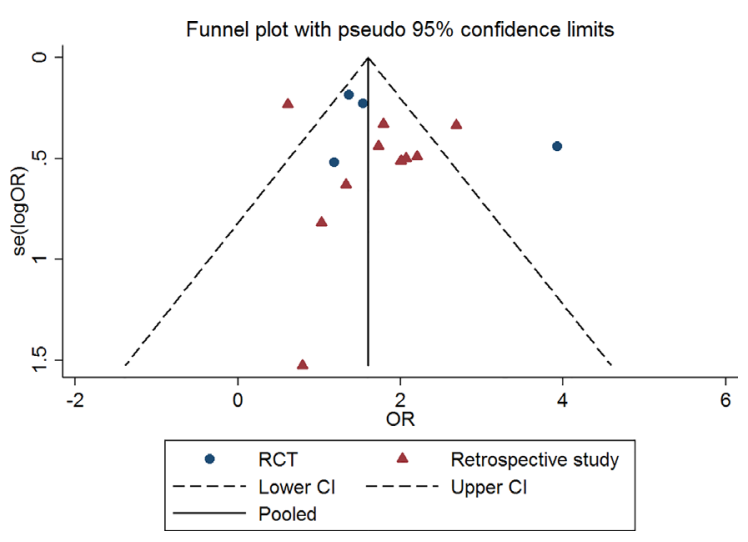

Figure S7 Funnel plot for the evaluation of publication bias of studies comparing DOACs and LWMHs for the CRNMB events in cancer patients. DOAC, direct oral anticoagulant; LMWH, lowmolecular-weight heparin; CRNMB, clinically relevant non-major bleeding. 
Table1 Baseline characteristics of included studies

\begin{tabular}{|c|c|c|c|c|c|c|c|c|c|c|c|}
\hline Study & Study period & Study type & Study groups and sample size & Treatment dose & $\begin{array}{l}\text { Treatment duration (interquartile } \\
\text { range) }\end{array}$ & Follow-up & Recurrent VTE (\%) & Recurrent PE (\%) & Major bleeding (\%) & CRNMB (\%) & Risk \\
\hline Raskob et al. & 2015-2016 & RCT & Edoxaban (n=522) vs. Dalteparin (n=524) & $\begin{array}{l}\text { Edoxaban: } 60 \mathrm{mg}, \mathrm{qd} \text {, after LMWH for } 5 \mathrm{~d} \\
\text { Dalteparin: } 200 \mathrm{IU} / \mathrm{kg} / \mathrm{d}, \mathrm{qd} \text { for } 1 \mathrm{mo} \rightarrow 150 \mathrm{IU} / \mathrm{kg} / \mathrm{d}, \mathrm{qd}\end{array}$ & $\begin{array}{l}\text { Edoxaban: } 211 \mathrm{~d} \text { (IQR:76-357); } \\
\text { Dalteparin: } 184 \mathrm{~d} \text { (IQR: 85-341) }\end{array}$ & $12 \mathrm{mo}$ & $7.9 \%$ vs. $11.3 \%$ & $5.2 \%$ vs. $5.3 \%$ & $6.9 \%$ vs. $4.0 \%$ & $14.6 \%$ vs. $11.1 \%$ & $\mathrm{~L}$ \\
\hline Young et al. & 2013-2016 & RCT & Rivaroxaban $(n=203)$ vs. Dalteparin $(n=203)$ & $\begin{array}{l}\text { Rivaroxaban: } 15 \mathrm{mg} \text {, bid, for the first } 3 \text { weeks } \rightarrow 20 \mathrm{mg} \text {, qd } \\
\text { Dalteparin: } 200 \mathrm{IU} / \mathrm{kg} / \mathrm{d} \text {, qd for } 1 \mathrm{mo} \rightarrow 150 \mathrm{IU} / \mathrm{kg} / \mathrm{d}, \mathrm{qd}\end{array}$ & $\begin{array}{l}\text { Rivaroxaban: } 5.9 \text { mo (IQR: } 2.5-6.0) \text {; } \\
\text { Dalteparin: } 5.8 \text { mo (IQR: } 3.0-6.0)\end{array}$ & $24 \mathrm{mo}$ & $3.9 \%$ vs. $8.9 \%$ & $2.0 \%$ vs. $4.4 \%$ & $5.4 \%$ vs. $3.0 \%$ & $12.3 \%$ vs. $3.4 \%$ & L \\
\hline McBane II et al. & 2015-2017 & RCT & Apixaban $(n=150)$ vs. Dalteparin $(n=150)$ & $\begin{array}{l}\text { Apixaban: } \\
10 \mathrm{mg}, \text { bid for } 7 \mathrm{~d} \rightarrow 5 \mathrm{mg} \text {, bid } \\
\text { Dalteparin: } 200 \mathrm{IU} / \mathrm{kg} / \mathrm{d} \text {, } \mathrm{d} \text { for } 1 \mathrm{mo} \rightarrow 150 \mathrm{IU} / \mathrm{kg} / \mathrm{d}, \mathrm{qd}\end{array}$ & N/A & $6 \mathrm{mo}$ & $0.7 \%$ vs. $6.3 \%$ & $0 \%$ vs. $0.7 \%$ & $0 \%$ vs. $1.4 \%$ & $6.2 \%$ vs. $4.2 \%$ & L \\
\hline Agnelli et al. & 2017-2019 & RCT & Apixaban $(n=576)$ vs. Dalteparin $(n=579)$ & $\begin{array}{l}\text { Apixaban: } \\
10 \mathrm{mg}, \text { bid for } 7 \mathrm{~d} \rightarrow 5 \mathrm{mg} \text {, bid } \\
\text { Dalteparin: } 200 \mathrm{IU} / \mathrm{kg} / \mathrm{d} \text {, qd for } 1 \mathrm{mo} \rightarrow 150 \mathrm{IU} / \mathrm{kg} / \mathrm{d} \text {, qd }\end{array}$ & $\begin{array}{l}\text { Apixaban: } 178 \text { d (IQR: 106-183); } \\
\text { Dalteparin: } 175 \text { d (IQR: } 79-183)\end{array}$ & $7 \mathrm{mo}$ & $5.6 \%$ vs. $7.9 \%$ & $3.3 \%$ vs. $5.5 \%$ & $3.8 \%$ vs. $4.0 \%$ & $9.0 \%$ vs. $6.0 \%$ & L \\
\hline Alzghari et al. & 2013-2015 & $\mathrm{RC}$ & $\begin{array}{l}\text { DOAC ( } n=48 \text {, rivaroxaban: } 44 \text { and apixaban: } 4) \\
\text { vs. Enoxaparin }(n=23)\end{array}$ & N/A & $\begin{array}{l}\text { DOAC: } 204 \mathrm{~d} \text { (range: 63-708); } \\
\text { Enoxaparin: } 136 \mathrm{~d} \text { (range: 2-590) }\end{array}$ & $6 \mathrm{mo}$ & $2.1 \%$ vs. $13.0 \%$ & $0 \%$ vs. $4.3 \%$ & $6.2 \%$ vs. $4.2 \%$ & N/A & M \\
\hline Chaudhury et al. & 2010-2015 & $\mathrm{RC}$ & Rivaroxaban $(n=107)$ vs. Dalteparin $(n=179)$ & N/A & N/A & $6 \mathrm{mo}$ & $4.9 \%$ vs. $11.1 \%$ & $5.0 \%$ vs. $3.1 \%$ & $2.8 \%$ vs. $1.1 \%$ & $9.3 \%$ vs. $4.5 \%$ & M \\
\hline Signorelli et al. & 2013-2015 & $\mathrm{RC}$ & Rivaroxaban $(n=18)$ vs. Enoxaparin $(n=26)$ & N/A & N/A & $6 \mathrm{mo}$ & $0 \%$ vs. $0 \%$ & $0 \%$ vs. $0 \%$ & $17.0 \%$ vs. $8.0 \%$ & N/A & M \\
\hline Nicklaus et al. & 2012-2015 & $\mathrm{RC}$ & Rivaroxaban (n=45) vs. Enoxaparin $(n=45)$ & N/A & $\begin{array}{l}\text { Rivaroxaban: } 169 \mathrm{~d} \text {; } \\
\text { Enoxaparin: } 110 \mathrm{~d}\end{array}$ & N/A & $9.0 \%$ vs. $13.0 \%$ & $9.0 \%$ vs. $4.0 \%$ & N/A & N/A & M \\
\hline Simmons et al. & 2013-2017 & $\mathrm{RC}$ & Rivaroxaban ( $n=98)$ vs. Enoxaparin $(n=168)$ & N/A & N/A & $12 \mathrm{mo}$ & $1.0 \%$ vs. $4.2 \%$ & N/A & $5.1 \%$ vs. $3.6 \%$ & $6.1 \%$ vs. $0.6 \%$ & M \\
\hline Xiang et al. & 2013-2016 & $\mathrm{RC}$ & $\begin{array}{l}\text { DOAC(n=71, Rivaroxaban:32, Dabigatran: } 17 \\
\text { and Apixaban:22) vs. Enoxaparin }(n=77)\end{array}$ & N/A & N/A & N/A & $5.6 \%$ vs. $11.7 \%$ & $1.4 \%$ vs. $2.6 \%$ & $2.8 \%$ vs. $3.9 \%$ & $8.5 \%$ vs. $6.5 \%$ & M \\
\hline Streiff et al. & 2007-2015 & $\mathrm{RC}$ & Rivaroxaban ( $n=685)$ vs. LMWH ( $\mathrm{n}=682)$ & N/A & $\begin{array}{l}\text { Rivaroxaban:1 mo; } \\
\text { LMWH: } 3 \mathrm{mo}\end{array}$ & $6 \mathrm{mo}$ & $13.1 \%$ vs. $17.6 \%$ & N/A & $6.7 \%$ vs. $4.1 \%$ & N/A & M \\
\hline Phelps et al. & 2010-2016 & $\mathrm{RC}$ & $\operatorname{DOAC}(n=190)$ vs. LMWH $(n=290)$ & N/A & $\begin{array}{l}\text { DOAC: } 153 \mathrm{~d} ; \\
\text { LMWH: } 160 \mathrm{~d}\end{array}$ & $6 \mathrm{mo}$ & $6.3 \%$ vs. $7.2 \%$ & N/A & $17.9 \%$ vs. $26.2 \%$ & N/A & $\mathrm{H}$ \\
\hline Uppuluriet al. & 2010-2015 & $\mathrm{RC}$ & DOAC ( $n=11)$ vs. LMWH ( $n=86)$ & N/A & N/A & N/A & $9.1 \%$ vs. $9.3 \%$ & $0 \%$ vs. $5.8 \%$ & $0 \%$ vs. $5.8 \%$ & $9.1 \%$ vs. $4.7 \%$ & M \\
\hline Pritchard et al. & 2012-2015 & $\mathrm{RC}$ & DOAC (n=80) vs. LMWH ( $(n=95)$ & N/A & N/A & N/A & $18 \%$ vs. $12 \%$ & N/A & $15 \%$ vs. $17 \%$ & $14 \%$ vs. $7 \%$ & M \\
\hline Lee et al. & 2012-2016 & $\mathrm{RC}$ & Rivaroxaban $(\mathrm{n}=78)$ vs. LMWH $(\mathrm{n}=203)$ & $\begin{array}{l}\text { Rivaroxaban: } 15 \mathrm{mg} \text {, bid, for } 21 \mathrm{~d} \rightarrow 20 \mathrm{mg} \text {, qd } \\
\text { Dalteparin: } 200 \mathrm{IU} / \mathrm{kg} / \mathrm{d} \text {, ad; } \\
\text { Enoxaparin: } 1 \mathrm{mg} / \mathrm{kg} \text {, bid; Nadroparin } 85.5 \mathrm{lU} / \mathrm{kg} \text {, bid }\end{array}$ & N/A & $12 \mathrm{mo}$ & $3.8 \%$ vs. $3.9 \%$ & N/A & $5.1 \%$ vs. $8.9 \%$ & $15.3 \%$ vs. $24.4 \%$ & M \\
\hline Lee et al. & 2012-2016 & $\mathrm{RC}$ & Rivaroxaban $(n=131)$ vs. Dalteparin $(n=73)$ & $\begin{array}{l}\text { Rivaroxaban: } 15 \mathrm{mg} \text {, bid, for } 21 \mathrm{~d} \rightarrow 20 \mathrm{mg} \text {, qd } \\
\text { Dalteparin: } 200 \mathrm{IU} / \mathrm{kg} / \mathrm{d} \text {, qd for } 1 \mathrm{mo} \rightarrow 150 \mathrm{lU} / \mathrm{kg} / \mathrm{d}, \mathrm{qd}\end{array}$ & N/A & N/A & $5.3 \%$ vs. $2.7 \%$ & N/A & $6.1 \%$ vs. $2.7 \%$ & $17.6 \%$ vs. $11.0 \%$ & M \\
\hline Ross et al. & 2014-2015 & $\mathrm{RC}$ & Rivaroxaban $(n=30)$ vs. Enoxaparin $(n=123)$ & $\begin{array}{l}\text { Rivaroxaban: } 15 \mathrm{mg} \text {, bid, for } 21 \mathrm{~d} \rightarrow 20 \mathrm{mg} \text {, qd } \\
\text { Enoxaparin: } 1 \mathrm{mg} / \mathrm{kg} \text {, bid; }\end{array}$ & N/A & $11.6 \mathrm{mo}$ & $3.3 \%$ vs. $6.7 \%$ & N/A & $13 \%$ vs. $11 \%$ & $7.3 \%$ vs. $6.7 \%$ & M \\
\hline Wysokinski et al. & 2013-2018 & $\mathrm{RC}$ & $\begin{array}{l}\text { DOAC(n=387, Rivaroxaban: } 163 \text { and } \\
\text { Apixaban:2244) } \\
\text { vs. Enoxaparin }(n=363)\end{array}$ & N/A & N/A & $6 \mathrm{mo}$ & $\begin{array}{l}\text { Rivaroxaban (or Apixaban) vs. } \\
\text { Enoxaparin: } 3.7 \%(6.5 \%) \text { vs. } \\
4.3 \%\end{array}$ & N/A & $\begin{array}{l}\text { Rivaroxaban (or Apixaban) } \\
\text { vs. Enoxaparin: } 6.6 \%(5.8 \%) \\
\text { vs. } 6.5 \%\end{array}$ & $\begin{array}{l}\text { Rivaroxaban (or Apixaban) vs } \\
\text { Enoxaparin: } 8.8 \%(0.6 \%) \text { vs. } \\
2.2 \%\end{array}$ & $M$ \\
\hline
\end{tabular}


TableS2 Quality assessment of non-randomized using risk of bias in nonrandomized studies of interventions (ROBINS-I).

\begin{tabular}{|c|c|c|c|c|c|c|c|c|}
\hline Study & $\begin{array}{l}\text { Bias due to } \\
\text { confounding }\end{array}$ & $\begin{array}{l}\text { Bias in selection } \\
\text { of participants } \\
\text { into the study }\end{array}$ & $\begin{array}{l}\text { Bias in } \\
\text { classification of } \\
\text { intervention }\end{array}$ & $\begin{array}{l}\text { Bias due to } \\
\text { deviations } \\
\text { from intended } \\
\text { interventions }\end{array}$ & $\begin{array}{l}\text { Bias due to } \\
\text { missing data }\end{array}$ & $\begin{array}{l}\text { Bias in } \\
\text { measurement } \\
\text { of outcomes }\end{array}$ & $\begin{array}{l}\text { Bias in } \\
\text { selection of } \\
\text { the reported } \\
\text { result }\end{array}$ & Overall \\
\hline Alzghari et al. & M & L & M & L & M & M & L & M \\
\hline Chaudhury et al. & $\mathrm{L}$ & L & M & L & L & M & L & M \\
\hline Nicklaus et al. & $M$ & L & M & L & M & M & $\mathrm{M}$ & M \\
\hline Simmons et al. & $\mathrm{L}$ & $M$ & M & $\mathrm{L}$ & L & M & L & M \\
\hline Xiang et al. & $\mathrm{L}$ & L & M & $L$ & M & M & M & M \\
\hline Pritchard et al. & $\mathrm{L}$ & L & M & M & L & M & M & M \\
\hline Lee et al. & $\mathrm{L}$ & L & $\mathrm{L}$ & M & L & M & $L$ & M \\
\hline Lee et al. & $\mathrm{L}$ & L & $\mathrm{L}$ & $\mathrm{L}$ & L & M & L & M \\
\hline Ross et al. & $M$ & L & $\mathrm{L}$ & $\mathrm{L}$ & L & M & M & M \\
\hline Wysokinski et al. & $\mathrm{L}$ & $M$ & $\mathrm{~L}$ & $\mathrm{~L}$ & L & $M$ & $\mathrm{~L}$ & M \\
\hline
\end{tabular}

$M$, moderate risk; L, low risk; $H$, high risk. 